\title{
O RETRATO POLÍTICO DE GERVÁSIO LOBATO
}

\author{
Manoel Levy Candeias ${ }^{1}$
}

RESUMO: Neste artigo discorremos sobre o modo como Gervásio Lobato faz um retrato crítico da sociedade portuguesa do final do século XIX, adaptando para seu contexto alguns recursos consagrados pelo francês Eugène Labiche. A partir de suas duas peças mais importantes, analisamos os resultados estéticos dessa transposição do modelo labichiano e avaliamos quais os novos significados que Lobato dá aos elementos do vaudeville.

PALAVRAS-CHAVE: Gervásio Lobato, teatro português, comédia, vaudeville.

ABSTRACT: On this article we discusses how Gervasio Lobato creates a critical portrait of the Portuguese society of the late nineteenth century, adapting to its context some resources devoted by the Frenchman Eugène Labiche. From his two major plays, we analyze the aesthetic results of this implementation of Labiche's model and evaluate the which new meaning Lobato gives to the vaudeville's elements.

KEYWORDS: Gervásio Lobato, portuguese theatre, comedy, vaudeville.

No final do século XIX, Portugal viu uma sequência de peças bem sucedidas dominar o palco do então famoso Teatro Ginásio, em Lisboa. Grande parte desse triunfo veio das encenações de obras de Gervásio Lobato, autor que deixaria para a posteridade um bom número de comédias, farsas, artigos, crônicas, traduções, imitações de peças estrangeiras e romances.

Nascido em 1850, esse atento observador da vida lisboeta fez sucesso por mais de dez anos com obras que tratavam de temas locais, em sua maioria ligados à vida da pequena e média burguesia lusitana da época. Esses são, pelo menos, os temas de Lobato mais salientados pelos estudiosos de sua obra e do teatro português.

De fato, a julgar pelas peças atualmente disponíveis para leitura nas bibliotecas mais importantes da capital portuguesa, a superficialidade e a falsidade com que ele retrata a sociedade burguesa de então são os motivos que rendem seus melhores momentos. Os exemplos mais notáveis da caricatura que Lobato faz dessas classes estão nas comédias Sua Excelência (1884) e O comissário de polícia (1890) consideradas por muitos suas grandes obras teatrais.

O que se deve ressaltar, entretanto, é que, apesar de explorarem o humor a partir de personagens da pequena e média burguesia, esses dois textos formam um quadro panorâmico e crítico do funcionamento da política portuguesa do período -

\footnotetext{
${ }^{1}$ Doutorando em Artes da Cena pelo Instituto de Artes, da Unicamp. Tem sua pesquisa apoiada pela Fapesp e cumpriu um estágio de estudos na Faculdade de Letras da Universidade de Lisboa sob o programa de bolsas da Capes.
} 
em torno da qual, evidentemente, tudo gravitava, não apenas suas personagens. Escritas com seis anos de diferença, cada uma dessas peças traz um estilo próprio e, por conseguinte, uma visão diferente sobre o mesmo problema, conforme veremos.

Sua Excelência mostra o encontro de um grupo de convivas de Lisboa em uma casa de campo situada em Sintra. Entende-se, pelas falas, que seus encontros habituais são para comer, conversar sobre banalidades e se divertir com jogos como voltarete ou outras distrações que pareçam convenientes ao tempo de ócio.

Apesar de não ser convidado, encontra-se, entre os frequentadores, Pombo, um senhor atrapalhado, que vive preso a seu passado, quando era político. Mostra-se sempre orgulhoso por ter sido três vezes deputado e volta, com frequência, a um assunto que parece ser sua maior frustração: o fato de nunca ter proferido um discurso na câmara. O impedimento veio, segundo conta, pela morte de seu burro, ocorrida justamente no dia em que ele se pronunciaria oficialmente pela primeira vez. O desastre não o impediu de ir à câmara naquele dia, mas lhe retirou a capacidade de falar em público, deixando um trauma nunca mais contornado. "O burro tolhera-me a eloquência" (LOBATO, 1893, p. 20), afirma desolado.

Mesmo sendo claramente rejeitado pelos outros, Pombo faz questão de participar da reunião na casa de Sintra, acompanhado de sua sobrinha, não menos desprezada do que ele. Depois de algumas maledicências e pequenos insultos a Pombo e a ela, resolvem ir embora por se sentirem desconsiderados naquele ambiente. Enquanto se afastam para pegar seus chapéus, vem a noticia de que caiu o ministério e que Pombo será convidado para assumir uma das pastas. Imediatamente, o comportamento de todos os personagens altera-se:

ERMEZINDA - E nós que o tratávamos sempre tão mal!

GEDEÃO - Mas sempre com amizade...

FAUSTO - Sempre! Eu desde o primeiro dia reconheci nele um homem superior.

RAYMUNDO - Tem, tem o tipo do gênio. Eu cá sou fisionomista. (LOBATO, 1893, pp. 35-36)

Desse ponto ao final da peça, quando cai novamente o ministério, a bajulação a Pombo e a supervalorização que ele faz da posição que ocupa são o motor da ação dramática e sua principal fonte de comicidade.

O interessante é que há certo didatismo no modo como Lobato trata do tema. A hipócrita transformação das personagens é muito evidente. Só não há alguém que 
declare explicitamente aquela falsidade porque todos estão juntos, praticam a mesma encenação, sem que seja necessário um convite. Em vez de alguém dizer que deveriam agir de outra maneira, considerando que agora Pombo ocupa uma posição que poderá render benefícios a eles, todos passam automaticamente a se dizer admiradores antigos do ministro etc. Estamos, portanto, diante de pessoas que, acostumadas ao jogo de mentiras, já não precisam combiná-lo. O que as torna mais cínicas e acentua a comicidade da peça. Há, talvez, menos disposição às atitudes interesseiras em Martha, que fica à parte, e em Ermezinda, que até ousa dizer que sempre maltrataram Pombo. Entretanto, como se vê no trecho acima, sua sinceridade é justamente o que proporciona aos outros a chance de estabelecer, com toda a hipocrisia que lhes convém, como se comportarão diante da nova situação hierárquica, em que o antes desprezado Pombo passará a ser ministro.

A única exceção realmente clara é Cezar, que poucas linhas depois tem uma fala que contribui para acentuar o didatismo da cena.

Quando Martha lhe sugere que interaja com os bajuladores, ele responde: "Nada, eu estudo esta soberba página de filosofia humana". (LOBATO, 1893, p.37) A página que ele estuda é justamente a transformação despudorada no comportamento de seus convivas ao saberem da iminente nomeação de Pombo ao ministério.

Sua fala parece ser direcionada à plateia para garantir que se repare no movimento que aquele grupo de pessoas está realizando. É claro que serve também para desenhar o caráter de Cezar e diferenciá-lo do restante, mas isso só reforça o valor de seu comentário, já que ele é um exemplo de boa conduta no meio de pessoas cujos princípios mudam com tanta facilidade, em função de interesses mesquinhos.

É com esse didatismo cômico que Gervásio Lobato constrói, em Sua Excelência, uma crítica à sociedade portuguesa. Pombo, uma personagem que não percebe quase nada a sua volta e vê nos cargos públicos a chance de ser alguém, ocupou por três vezes um lugar na câmara e ainda é nomeado ministro de obras públicas, sem ter nenhum conhecimento sobre a área. Certamente, ninguém gostaria de ter alguém como ele em qualquer função política que fosse, mas Portugal retratado por Lobato nessa peça o tem em diferentes cargos e por mais de uma vez. Além disso, quase todas as personagens com quem ele se relaciona têm o comportamento volúvel que comentamos, agindo apenas de acordo com a conveniência, sem escrúpulo algum.

Em $O$ comissário de polícia não há esse didatismo e a relação com o cargo público já é um pouco diferente. Faustino, personagem que no meio da trama se torna 
governador civil substituto, não valoriza tanto a sua posição, não se mostra tão deslumbrado, até porque não sofre da falta de estima e de bons tratos que vemos em Pombo. Para o protagonista de $O$ comissário de polícia ser governador não é a chance de ser alguém, é a oportunidade de ter privilégios. E é, acima de tudo, a possibilidade de tentar impôr uma explicação pouco convincente quando se descobre que ele é amante da moça que portava a joia que fora roubada de sua esposa - crime praticado por ele próprio. Na última cena, ao ser desmascarado em uma situação que deixa pouca margem para se acreditar em qualquer explicação que contrarie as evidências de uma relação extraconjugal entre ele e a moça que porta as joias de sua esposa, ele imediatamente se aproveita do cargo político:

D. MARIA - Oh! tratante! Pois és tu!

FAUSTINO (muito risonho) - Sou eu, sou eu, e tenho muita honra nisso! Bravo, senhor comissário! Bravo!

PYGMALIÃO - Então ele aplaude-me? (...)

D. MARIA - Mas o que quer dizer isto?! Explica-te!

FAUSTINO - Quer dizer que eu quis verificar pelos meus próprios olhos como os meus subordinados cumprem os seus deveres. E estou contente, contentíssimo!

BERNARDO - Pois eu é que não estou, quero saber...

FAUSTINO - Estou contentíssimo com você também, Bernardo, andou muito bem nesta diligência, e vou arvorá-lo em cabo de polícia secreta (...)

D. MARIA - Mas como soubeste tu que as joias e aquela rapariga...

FAUSTINO - Como soube? Oh! isso é que não posso dizer. É segredo de polícia. Não é assim, senhor comissário?

PYGMALIÃO - Exatamente! É segredo de polícia!

(LOBATO, 1919, p.92)

Mesmo diante de uma explicação tão pouco convincente, ninguém ousa questionar o governador civil. A única exceção é sua esposa: "Pois sim, deixa estar que lá em casa te direi o segredo de polícia!” (LOBATO, 1893, p. 92), afirma ela, deixando claro que na vida doméstica a máscara pública não terá efeito.

Esse é um ponto interessante, que ocorre de modo semelhante em Sua Excelência. Como não tem quem apresentar como cônjuge em uma importante cerimônia pública, Pombo acaba se casando com sua sobrinha, com quem fingia estar em matrimônio para ver se lhe conseguia um marido. Afinal, "em Lisboa as mulheres casadas têm mais procura que as solteiras" (LOBATO, 1893, p. 25), afirma, revelando seu peculiar estratagema. E logo que assinam o papel, a sobrinha passa a comandar a vida doméstica, na qual, também neste caso, o cargo político não determina a posição 
hierárquica. Pouco depois de consumadas as núpcias, a relação é estabelecida:

CLARA - Ó Pombo, diga lá dentro à criada que ponha luzes na sala. POMBO - Como? (A Cezar) Então ela manda-me como um criado? CEZAR - Meu amigo, começa a ser marido; obedeça. POMBO - Perdão! eu só obedeço às indicações constitucionais... CLARA - Não ouviu, Pombo? (LOBATO, 1893, p.153)

Essa cena e a fala de D. Maria quase ao final de $O$ comissário de polícia contribuem para sublinhar a importância dos cargos de governador e ministro e, em contraponto, a vulgaridade de Faustino e Pombo. O valor está na posição privilegiada dentro do quadro social, não na pessoa que o detém. E é isso que Lobato trabalha de modo bem diverso em cada uma das peças. Pombo confunde-se com o cargo de ministro e faz questão de reafirmá-lo a todo instante:

POMBO - (na sala de entrada, preparando-se para aparecer. Ao correio) Ande! Anuncie-me!... Voz sonora e inteligível.

CLARA (dentro) - Ó tio, olhe que não é costume... Pombo - Deixa-lo não ser. O ministro sou eu! (LOBATO, 1893, p.42)

Já as personagens de seu entorno não parecem preocupadas com o ar de superioridade que ele procura estabelecer. Elas desejam apenas estar em posição privilegiada dentro da hierarquia social. Buscando convencer sua filha Martha a se casar com Pombo, Eleutheria diz: "Por força! Quero ser sogra dum ministro de estado! quero ser sogra da situação!” (LOBATO, 1893, p.80). Uma visão bem mais objetiva, que a aproxima de Faustino, o protagonista de $O$ comissário de polícia, que bem poderia estar entre os coadjuvantes de Sua excelência. Porque sua preocupação não é ser valorizado pelos outros, é contornar suas dificuldades particulares. Para isso se vale do cargo de governador.

Nesse aspecto, podemos dizer que os dois protagonistas expressam a hibridez da monarquia constitucional, regime que duraria em Portugal até 1910, quando foi instaurada a primeira república. Pombo representa uma geração que ainda associa valores de nobreza e fidalguia às posições políticas e busca, por meio delas, afirmar sua identidade social. Algo que ainda guarda valores da monarquia, em que, grosso modo, os seres de origem nobre é que comandam a nação. Por outro lado, Faustino, da peça de 1990, que trai a mulher autoritária com uma criada e aceita ser governador 
civil apenas para encobertar suas mentiras, aponta para um comportamento mais moderno, da falsa democracia, dos regimes compostos por câmaras, ministérios etc., criando os desejados empregos diretos e indiretos. (Embora tudo isso já existisse no regime do período em que as duas peças foram escritas. As mudanças só viriam vinte anos depois da segunda). Porém, ao contrário do que faz em Sua excelência, Lobato não explora essa caça por oportunidades em $O$ comissário de polícia. Assim, mesmo tendo a ingerência do país como fundo temático comum, essas duas peças são muito diferentes. Pelo que dissemos sobre as personagens e pelas implicações estéticas dessas opções. Vejamos uma a uma.

É comum a diversos estudos a afirmação de que Gervásio Lobato influenciouse pela dramaturgia de Eugène Labiche. Não discordamos disso, sobretudo no caso de Sua excelência. E nesse aspecto há grande mérito, porque Lobato não reproduz simplesmente a estrutura labichiana, ele a remodela para que traduza as questões que ele busca retratar da sociedade portuguesa de sua época. A sequência de enganos que dá à obra de Labiche o movimento descrito por Henri Bergson como "efeito bola de neve" (BERGSON, 2011, p. 59) ganha, em Lobato, um ritmo semelhante, mas com um fundamento novo. Não se trata, como em O chapéu de palha da Itália, por exemplo, da história de um grupo de pessoas que, indiretamente ligadas ao responsável pelas mentiras, acabam entrando, involuntariamente, nas confusões que ele cria. É quase toda a coletividade que pratica intencionalmente uma atitude absurda atrás da outra, em função de uma situação transitória, que não existia no início e deixa novamente de existir ao final: a nomeação de alguém próximo a uma cargo político.

O movimento da ação dramática de Sua excelência é provocado pelas atitudes intencionais de personagens secundárias ambiciosas e volúveis, que, a cada passo, criam mais complicações na busca de obter vantagens. O resultado é que Pombo, o protagonista, não age muito, embora tenha sua caricatura muito bem explorada. A ação vem mesmo das outras personagens, que são, por conta disso, melhor desenvolvidas por Lobato do que os coadjuvantes de Um chapéu de palha da Itália. A diferença entre o texto do francês e Sua excelência é que o primeiro mostra as

\footnotetext{
${ }^{2} 0$ que Bergson denomina efeito "bola de neve" consiste no movimento crescente que a soma de enganos produz em uma peça de vaudeville, gênero que tem em Eugène Labiche um de seus maiores nomes. A trama inicia-se com um engano simples, de pequenas consequências, mas a falta de um desmentido vai ampliando a complexidade da situação, envolvendo outras personagens e valores, até que, ao final, o problema atinge grandes dimensões, mas é resolvido com certa simplicidade, e ganha novamente sua dimensão inicial.
} 
confusões que um engano individual pode causar na coletividade e o segundo mostra como a coletividade portuguesa pode ser volúvel a ponto de criar um movimento que se assemelha ao de uma comédia de enganos. Algo que podemos entrever como parte do pensamento de Lobato ao ler o seguinte trecho de uma crônica sua:

Uma das coisas que mais nos diverte no nosso país é o reviramento completo e constante da chamada opinião pública, as cambalhotas permanentes que ela dá em todos os assuntos, com uma rapidez tal, que nunca é possível saber ao certo quando ela está pelos pés ou pela cabeça. (LOBATO, 1882, p. $281^{3}$ )

Em $O$ comissário de polícia ele traz mais sutileza a essa questão, não a tem como tema principal. Parece ser um estágio posterior, quando já não vale a pena investir na crítica escancarada à falta de escrúpulos de quem se envolve com a política. O problema está presente até com certa naturalidade, como se já fizesse parte do dia a dia. O foco da trama é a investigação que Pygmalião e Bernardo fazem para descobrir onde foram parar as joias de D. Maria e o que aconteceu com a esposa de Bernardo, que à leitura sabemos ser amante de Faustino. O ladrão e adúltero é justamente aquele que, por meio de um contato, consegue ser nomeado governador civil substituto. Mais uma vez, parece não haver critérios objetivos para a distribuição de cargos, é tudo baseado em relações pessoais. Porém, transferindo as atenções para a busca policial, Lobato não valoriza tanto a questão. A comédia de costumes de antes ganha ares de novela policialesca, com um comissário de polícia que tem algo do Pombo, de Sua excelência, ao levar demasiadamente a sério sua profissão. Porém, de nada adianta sua postura quando a pessoa que ele investiga é o governador civil. Nesse importante momento, a valorização do cargo público, que parecia ter sido deixada de lado pelo autor, torna-se tema central novamente. E ao utilizar esse caminho, em que deixa a problemática em segundo plano para fazê-la surgir, ao final, como fator determinante para o destino da trama, Lobato acaba delineando uma situação mais crítica do que a que vemos em Sua excelência. Já não se vê tão explicitamente o que é feito dos cargos públicos. Entretanto, os problemas a isso relacionados continuam a existir e alteram significativamente o rumo das coisas.

Com isso, Lobato toca nos mesmos temas, mas substitui a realidade cômica e

\footnotetext{
${ }^{3}$ In OLIVEIRA, Maria Luísa Rodrigues. Para uma construção do cômico em Camisa de Gervásio Lobato. Dissertação de Mestrado. Faculdade de ciências sociais e humanas, da Universidade nova de Lisboa. Lisboa: Universidade nova de Lisboa, 1996.
} 
atrapalhada da ambição coletiva de Sua excelência pela inútil, ingênua e também atrapalhada busca da verdade do comissário de polícia que dá nome à outra peça. Não por acaso, o último ato de $O$ comissário de polícia se passa em um baile de máscaras, onde, ao final, os suspeitos são presos e obrigados a tirar os disfarces. Porém, conforme vimos, ao cair uma máscara, surge outra, a de governador civil, contra a qual todos são impotentes e diante da qual sempre se espera receber algum privilégio. E são essas as armas usadas por Faustino. Ao menos para silenciar o comissário de polícia e para evitar uma agressão do marido de sua amante.

Essa estrutura e a opção pelo tom policialesco não provocam o movimento coletivo de Sua excelência, nem a sequência de enganos de Um chapéu de palha da Itália, embora tenha alguns mal entendidos. A solução encontrada por Lobato para dar um ritmo intenso à comédia foi, novamente, valorizar os coadjuvantes. Porém, nesse caso, por não estarem tão voltadas para o protagonista, as intenções das outras personagens acabam criando subtramas que diluem a força da peça, fazendo-a oscilar entre os diversos acontecimentos paralelos. Isso não retira as qualidades, mas o resultado não é tão satisfatório quanto o de Sua excelência.

Ainda assim, podemos afirmar que com O comissário de polícia e Sua excelência Gervásio Lobato cria um pequeno quadro da sociedade portuguesa do final do século XIX, com um humor leve e inteligente, que utiliza, de maneira muito própria, alguns recursos bastante característicos do vaudeville labichiano. Por esse caminho, deixa sua crítica à burguesia e à política de seu país. E deixa também um conjunto de obras que fez bastante sucesso à época, abrindo caminho para outros autores. Vale dizer que há qualidades em outras de suas peças, inclusive na ótima farsa $O$ festim de Balthazar, mas nas duas sobre as quais aqui discorremos é que ele trata melhor de seu tema de maior amplitude.

\section{Referências bibliográficas:}

BARATA, José Oliveira. História do teatro português. Lisboa: Universiade aberta, 1991.

BERGSON, Henri. O riso. Trad. Ivone Castilho Benedetti.. São Paulo: Martins Fontes, 2001

CRUZ, Ivo Duarte. História do teatro português. Lisboa: Editorail Verbo, 2001.

GUINSBURG, Jacó, FARIA, João Roberto, LIMA, Mariângela Alves de. (org.). 
Dicionário do teatro brasileiro. São Paulo: Perspectiva: Sesc São Paulo, 2006.

LABICHE, Eugène. Um chapéu de palha de Itália e a viagem do senhor Périchon. Trad. Eduardo Jacques. Porto: Livraria Civilização - editora, 1968.

LOBATO, Gervásio. A condessa Heloísa. Lisboa: Empresa literária de Lisboa, 1892. Sua excelência: comédia original em três atos. Lisboa: Editor Baeta Dias, 1893.

O festim de Balthazar: farsa original em um ato. Lisboa: G.L., 1892. . O comissário de polícia: comédia original em quatro atos. Lisboa: Editor Arnaldo Bordalo, 1919.

MINOIS, Georges. História do riso e do escárnio. Trad. Maria Elena O. Ortiz Assumpção. São Paulo: Editora UNESP, 2003.

OLIVEIRA, Maria Luísa Rodrigues. Para uma construção do cômico em Lisboa em Camisa de Gervásio Lobato. Dissertação de Mestrado. Faculdade de ciências sociais e humanas, da Universidade nova de Lisboa. Lisboa: Universidade nova de Lisboa, 1996.

PAVIS, patrice. Dicionário de teatro. São Paulo: Editora Perspectiva, 1987.

PICCHIO, Luciana Stegagno. História do teatro portugês. Trad. Manuel de Lucena. Lisboa: Portugália, 1964.

REBELLO, Luiz Francisco. 100 anos de teatro português. Porto: Brasília editora, 1984.

- Três espelhos: uma visão panorâmica do teatro português do liberalismo à ditadura (1820-1926). Lisboa: Imprensa Nacional-Casa da Moeda, 2010. 